\title{
La evangelización en el mundo contemporáneo
}

\author{
Juan Ramón Moreno, \\ Centro de Reflexión Teológica, \\ San Salvador.
}

\section{Introducción}

El término "evangelización" es complejo. Nominalmente podriamos definirio como comunicación de una buena noticia. Pero son diversas las realidades que convergen para hacer que la buena noticia sea noticia y sea buena: su origen, su contenido, su portador, su receptor, que es lo que hace que esta noticia sea buena para este receptor, etc.

Por otro lado lo que aqui pretendemos esclarecer de alguna manera no es la evangelización en general, sino la evangelización cristiana. No cualquier "buena noticia" que se anuncia es cristiana, como tampoco es cristiano cualquier modo de anunciarla 1

\subsection{Importancia del tema}

La importancia del tema es crucial. Por eso se planted con tanta insistencia en las comunidades vivas de la Iglesia, sea en forma directa sea en forma de pregunta sobre la misión de la Iglesia, la misión de la vida consagrada, o de las comunidades de base, o de la parroquia... Tambien el magisterio oficial de la Iglesia le dedica especial atención: el Sínodo de 1974, la Evangelii Nurtiandi, la conferencia de Puebla, el enfoque dado a la celebración de los 500 atlos de evangelización de nuestro continente, en el cual se enfatiza in "nueva evangelización," no son sino expresiones de una honda preocupación.2

Y no podía ser de otra manera si, como lo dice el sinodo de 1974 y lo recoge la Evangelii Nuntiandi, "la trea de la evangelización de todos los hombies constituye la misión esencial de la iglesia," y si, como insiste Pablo VL, "evangelizar constimye en efecto la dicha y la vocación propia de la Iglesia, su iden- 
tidad más profunda. Ella existe para evangelizar" (EN 14). Está, pues, claro que en la evangelización se esta jugando la razón de ser de la Iglesia y, dentro de ella, la de la vida consagrada y la de todos los movimientos de vida cristiana. Por ello la evangelización no es un tema más entre los varios que se pueden y deben tratar, sino que es el tema central. Al preguntarnos por lo que significa evangelizar nos estamos preguntando por la esencia misma de la Iglesia.

Pienso que esto está ya muy claro en la conciencia de la Iglesia y en nuestra propia conciencia como hombres y mujeres que buscamos vivir nuestra vocación cristiana y eclesiol en la vida consagrada. Pero quizás deberiarnos clarificar más lo que esto exige de la Iglesia y de las diversas instituciones eclesiales.

\subsection{Dificultades $y$ exigencias}

Hoy encontramos especiales dificultades para evangelizar el mundo moderno, pero si queremos ser honrados debemos preguntarnos: ¿esas dificultades provienen únicamente de las resistencias y obstáculos peculiares del mundo de hoy, como pueden serlo el ateísmo, el secularismo, el consumismo, el hedonismo y todos los demás "ismos" que podemos seguir aftadiendo? ¿O provendrán también de una Iglesia que no ha sabido configurarse ella misma y estructurar su pastoral de un modo que potencie su capacidad de transmitir creiblemente a los hombres y mujeres de hoy la buena noticia de Jesis?

Nadie niega que un mundo cambiado exige nuevas formas de evangelizar, pero ¿no exige también un nuevo modo de ser Iglesia, y para nosotros, dentro de ella, un nuevo estilo de vida consagrada? ¿Cómo ser buena noticia para el mundo de hoy? La Iglesia no es una Iglesia que se constituye primero como lal y después, ya constituida, recibe el evangelio para transmitirlo. De ninguna manera. La Iglesia es constitutivamente misión y su misión es evangelizar. La Iglesia de Jesús se define y constituye como tal evangelizando. El Espíritu Santo que hace nacer a la Iglesia se da como fuerza para la realización de esta misión: "Y soplando sobre ellos les dijo: "como el Padre me envió yo los envió a ustedes" (Jn 20,21). "Recibirán una fuerza, el Espíritu Santo que descenderá sobre ustedes, para ser testigos míos en Jerusalén, en Judea, en Samaria, hasta los confines de la tierra" (Hch 1,8).

r Se trata de dar testimonio de Jesús, evangelio definitivo de Dios. El más antiguo de los evangelios que conocemos se titula así: "Comienzo de la buena noticia de Jesús, el Cristo" (Mc 1,1). Pero no debemos olvidar que anteg que ser el Cristo proclamado es el Jesús que proclama, el Jesús que evangeliza. Es mérito de la Evangelii Nuntiandi iluminar el tema de la evangelización a partir de Jesús "el primero y más grande evangelizador" (EN 6). Esto lleva a entender la evangelización no en abstracto, sino desde la concreción histórica de Jesús de Nazaret Es mirando a Jesús como la Iglesia aprende a ser evangelizadora. 


\section{Jesús y la evangelización}

\subsection{El principio y fundamento de la evangelización}

Lo que hay que aprender en primer lugar es qué es lo primero en la evangelización. Lo primero no simplemente en el sentido temporal, sino en un sentido radical: qué es lo más fontal, la raíz de que brota y que al mismo tiempo sostiene y nutre todo el proceso evangelizador; su principio y fundamento, es decir, aquello que fundamenta y origina la evangelización siendo principio de un modo de ser y de actuar que, precisamente por tener tal fundamento, se hace buena noticia

Cuando Jesús propone la parábola del samaritano al escriba que pregunta por el mandamiento primordial nos da importantes pistas para comprender lo que significa evangelizar, constituirse en buena noticia Para aquel hombre, asaltado por los bandoleros en el camino de Jerico y abandonado all medio muerto, no fue buena noticia el sacerdote que lo vio, dio un rodeo y pasó de largo; ni lo fue tampoco el levila que pasó después. Quien sí fue buena noticia fue el samaritano, quien fue capaz de captar su necesidad, dejarse afectar por ella y actuar eficazmente para salvarlo de ella

Me voy a permitir analizar un poco más detenidamente lo esencial de esta parábola. Tirado en el camino está ese hombre malherido y a punto de perder una vida que se le escapa. De pronto aparece el samaritano y, nos dice tex walmente el evangelio, "al verle tuvo compasión y acercándose vendó sus heridas echando en ellas aceite y vino, y montíndole sobre su propia cabalgadura, lo llevó a una posada y cuidó de él." Todo comienza con la expresión "viéndole," el gesto de mirar, la toma de conciencia de que ahr hay una presencia Pero esa toma de conciencia de esa presencia sufriente y necesitada, no es por sí sola generadora de esperanza y gozo, no es buena noticia. También el sacerdote y el levita que pasaron antes "vieron," pero el modo de mirar, lo que hay detrás de esa mirada no es capaz de impulsar los pasos subsiguientes que dan origen a la buena noticia: "y viéndolo, dieron un rodeo y pasaron de largo." No basta mirar, es fundamental lo que detrás de la mirada se esconde y que genera distintas maneras de mirar, ojos diferentes, en el samaritano y en los dos servidores del templo. Estos miran insolidariamente, desde la distancia, sin dejarse afectar por la situación del otro, que en el fondo no les importa lo suficiente como para hacer el esfuerzo de alterar sus planes de viaje y acercarse. No hay amor compasivo, capacidad para dejarse preocupar por la suerte del otro y, ante su precariedad, ocuparse de él. Muy distinta es la mirada del samaritano. Mirada de quien estŕ abierto a la situación de los otros, porque tiene un corazón solidario, porque es capaz de amor comprometido. Como consecuencia de ello lo que su mirada capta de sufrimiento, de realidad acuciante, le afecta y le afecta de tal manera que "sintí compasión." Lucas emplea aquí el verbo griego splanchnizomai, que repetidas veces aplican los evangelios a Jesús. Significa literalmente conmoverse las entraflas. Y las entraflas se conmueven cuando en ellas ha entrado algo extraño que las irrita, algo 
que hay que acabar expulsando para quedarse tranquilo. Es compasión en el sentido fuerte de la palabra. La solidaridad con el otro lleva a identificarse con él de forma tal que su dolor, su pasión, se hacen propios (com-pasión) y de tal manera me duelen que se me hacen insoportables: hay que alivarlos, hay que hacer algo por cambiar la situación de sufrimiento. De ahí brota la acción, como un hacer algo que pone remedio al dolor del otro que es también mi dolor.

En consecuencia, con esto nos dice la parábola que el samaritano "se acercó." La identificación solidaria con el otro le lleva al movimiento de acercarse, de hacerse próximo al otro, entrar en su mundo para poder conocer mejor su necesidad y actuar sobre ella. Pero esto exige salir del propio mundo, de los propios intereses y preocupaciones, alterar los propios proyectos, para acomodarse a lo que el servicio a la vida del otro reclama. El samaritano deja de lado sus planes de viaje para entrar en la realidad doliente del herido, ocuparse de él y llevarlo a la curación, a la vida. Ha sabido hacerse buena noticia para el hombre asaltado por los ladrones. La única gramática por medio de la cual se puede expresar la buena noticia cristiana es la gramática del amor misericordioso, la gramática de la solidaridad con el otro. Y en la raíz, en el origen fontal de esa buena noticia están las entraflas de misericordia.

Es significativo que esta forma de actuar, que Jesús presenta como modelo ("haz tú lo mismo"), no hace sino reflejar lo que es el modo mismo de hacer de Jesús. Llama la atención el gran número de veces en que el evangelio nos describe la actividad de Jesús a través de una secuencia de tres gestos que se enlazan inseparablemente entre sf: "fijando en él su mirada, lo amó y le dijo..." (Mc $10,21)$, "vio mucha gente, sintió compasión de ellos y curó a sus enfermos" (Mt 14,14). Antes de la palabra o de la acción, el gesto de mirar, expresión de un corazón misericordioso, preocupado por calar la realidad como es, en su crudeza, sin escamotear nada. $Y$ cuando esa situación en que se encuentra el otro es una situación doliente, el corazón se deja afectar por ese dolor y la mirada se hace compasión: "esplanchnisthe," "se le conmovieron las entraftas."

Por otro lado, es lo más frecuente que esa mirada recaiga en lo que los evangelios denominan "ochlos," muchedumbre, gentío. Ya en el capítulo cuarto, en el comienzo mismo de la vida pública de Jesús, cuando el evangelista Mateo presenta uno de esos sumarios que después se repiten y que recogen lo más fundamental de la actividad mesiánica de Jesús, leemos textualmente:

Su fama llegó a toda Siria y le traían todos los pacientes aquejados de enfermedades y sufrimientos diversos: endemoniados, lunáticos, paralíticos, y los sanó. Y lo seguía una gran muchedumbre, de Galilea, Decápolis, Jerusalén, Judea y del otro lado del Jordán (Mt 4, 24-25).

San Marcos en el capitulo 3 nos describe todavia más esa multitud que acosa a Jesús hasta el punto de que pide que le preparen una barca para que no lo opriman, "pues habiendo curado a muchos, cuantos padecían dolencias se le echa- 
ban encima para tocarle" (Mc 3,10). Se trata indudablemente de una mulitud doliente, una multitud de harapientos, de necesitados y enfermos que en Jesús descubren algo que despierta en ellos la esperanza: algo hay en Jesús que les dice que su realidad de sufrimiento puede ser transformada, que las cosas van a cambiar. Eso los lleva a buscar a Jesús ansiosamente hasta el punto de abalanzarse sobre él y oprimirlo y no dejarlo ni siquiera, como algo más adelante describe el evangelista, espacio para comer. Incluso cuando, buscando un momento de respiro, pide Jesús que lo pasen en barca al otro lado del lago, allí está ya la multitud esperándolo. "Y al desembarcar, vio mucha gente, sintió compasión de ellos y curó a sus enfermos" (Mt 14,14).

Este es el mundo al cual Jesús se acerca, al cual entra, por cuya realidad se deja afectar, y en cuya transformación se compromete. Cuando los discípulos de Juan le preguntan si es él el que ha de venir, su respuesta es "vean y den testimonio de lo que han visto y oído." Y ¿que es lo que han visto y oído? Que ya la realidad se transforma: "los cojos andan, los ciegos ven, los muertos resucitan y a los pobres se les anuncia la buena noticia" (cfr. Mt 11,3-6). Hay un cambio de realidad que es generador de vida y por ello mismo generador de esperanza. Es la compasión que busca efectivamente cambiar lo que no deja que el otro viva.

\subsection{La "buena noticia" de la encarnación}

Al pretender comprender lo que significa la buena noticia desde la perspectiva del misterio global de la encamación, nos encontramos con la misma raíz de donde brota la posibilidad de la buena noticia: la misericordia. Cuando san Ignacio de Loyola en sus Ejercicios espirituales presenta la contemplación de la encarnación, un pasaje que es clave para comprender la espiritualidad ignaciana y de los jesuitas, contrapone como en dos planos diferentes, por un lado, el mundo empecatado y, por otro lado, el Dios trinitario que mira a ese mundo. Es un mundo insolidario, un mundo perdido, un mundo sin esperanza. Y Dios mira a ese mundo del único modo con que Dios sabe mirar, con mirada de Padre, con una mirada que surge de la preocupación amorosa por lo que pasa en el mundo. Y a pesar de lo que esa mirada ve, y precisamente por lo que ve, brota en el corazón de Dios, por hablar de alguna manera, la temura compasiva, se conmueven las entraftas misericordiosas de Dios. "Tanto amó Dios al mundo que entregó a su hijo único" (Jn 3,16). Y san Pablo dirá: "la prueba de que Dios nos ama es que Cristo, siendo nosotros todavía pecadores, murió por nosotros" ( $R m 5,8)$. La respuesta de Dios a este mundo tirado en el camino, a este mundo agonizante con una muerte sin esperanza es, como en la parábola del samaritano, acercarse al mundo, entrar en el mundo: "el verbo se hizo carne y puso su tienda entre nosotros" (Jn 1,14). Es el amor que se acerca todo lo que es posible acercarse a nuestra historia de insolidaridad, dolor y frustración, pero no para dejarla tal cual está, sino para transformarla, para hacer que sea lo que debe ser. Ya no será posible encontrar a Dios al margen de la historia de los hombres y de la lucha por hacerla transparencia de Dios, historia de salvación. 
Así la buena noticia existe simplemente porque Dios es un Dios con entraftas de misericordia, un Dios que busca nuestro bien no porque nosotros seamos buenos, sino porque él es bueno, que nos ama no porque seamos amables, sino porque él es amor. Y esa misericordia actúa a través del acercamiento, a través del hacerse solidario, del identificarse con aquel a quien se ama y que recibe así la buena noticia de que algo fundamental va a cambiar en su situación. San Pablo describe ese movimiento con la expresión del anonadamiento, del rebajamiento. Es entrar en el mundo pequeño del otro, asumir la limitación de la carne humana La palabra increada, que estaba junto a Dios, que era Dios, se hace ahora palabra humana, se expresa en arameo, se encarna en una cultura concreta, entra en la historia de un pueblo. Y este movimiento supone además un momento de pasividad: hacerse came es dejarse dar came. En todo acercamiento hay un momento de recepción, de dejarse enseffar por el otro, que me da su realidad. En el seno virginal de María, el Verbo se deja dar cuerpo, cuerpo historico y humano. Y esa came humana nacera, como toda carne humana, pequeffa y limitada. El niño recién nacido, quien, envuelto en pañales como símbolo de su debilidad, necesita ser criado y ensef́ado, quien tiene que ser ayudado a "crecer en edad, sabiduría y gracia," expresa con imponente plasticidad lo que encamarse significa. Tanto Mateo como Lucas, los dos evangelistas de la infancia, dan gran importancia, aunque en conlextos diferentes, a la genealogía de Jesús. Genealogias que para el lector moderno resultan aburridas y carentes de especial significado representan, en la mentalidad de los evangelistas, la manera de expresar que la encarnación exige insertarse en la vida de un linaje, de un pueblo concreto, en este caso el judío, del que se recibe la historia, la cultura, y de cuyo destino uno se hace parte. Tomar cuerpo real es incorporarse a las luchas y esperanzas de un pueblo en marcha. El autor de la carta a los Hebreos, describe con tremenda fuerza este movimiento solidario de la encamación afirmando de Jesús que "ha sido probado en todo igual que nosotros, excepto en el pecado" (Heb 4,15).

La importancia que tiene en Jesús este momento de pasividad - dejarse dar cuerpo, dejarse dar cultura, dejarse dar identidad-queda resaltada con esos más de 30 afios de silencio y oscuridad en Nazaret, en que todo lo que hace Jesús es simplemente ser uno más dentro de la realidad de su pueblo. Sólo después que se ha dejado dar palabra, que se ha impregnado del modo de ser de su pueblo, sale, movido por el Espíritu, a realizar de manera abierta su actividad mesiánica. Y todavía su primer gesto público será solidarizarse con el pueblo pecador y, como uno más entre ellos, recibir de manos de Juan el bautismo de penitencia.

\subsection{Ser "buena noticia" en un mundo dividido: parcialidad hacia los pobres}

Pasando ahora a fijamos en la actividad pública de Jesús, parece bastante claro que el horizonte fundamental dentro del que toda ella se desarrolla es lo que Jesús llama el reino de Dios. Como constatan los evangelios sinópticos, lo que Jesús proclama es el reino de Dios como realidad que viene y que al imumpir en la his- 
toria la va cambiar de raiz. El hecho de que el centro de la predicación de Jesús no es Dios sin más, sino el reino de Dios, tiene particular importancia. El Dios de Jesús no es un Dios que se desentiende de lo que acontece en el mundo. Por el contrario, se preocupa por lo que sucede en la historia y le importa y afecta la situación de la humanidad, hasta el punto de que, como acabamos de considerar, se hace por la encamación parte de esa historia.

Pero éste es un mundo dividido, y en un mundo dividido la buena noticia tiene que ser necesariamente parcial. No suena de la misma manera en los oídos de todos. Ya en el contexio judío, en el cual Jesús realiza su misión, el anuncio del reino que se acerca, evoca la presencia de un Dios que viene a hacer justicia, a hacer que las cosas sean como deben ser. En toda sociedad hay fuertes y débiles, poderosos e impotentes. La insolidaridad del corazón del hombre hace que las más de las veces el poderoso utilice su fuerza para aprovecharse del débil, profanando su dignidad y conculcando sus derechos. El débil no tiene cómo defender su derecho; sólo le queda o morir o resignarse á soportar la opresión y el abuso que le impone el egoísmo del poderoso. Esto descncadena una lógica histórica en la cual el poderoso se hace cada vez más poderoso a costa de hacer que el débil sea cada vez más débil y sometido a la arbitrariedad del fuerte. La idea de un rey justo que viene a ejercer efectivamente su soberania, supone que va a venir a establecer la justicia defendiendo el derecho del pobre y débil, que no liene recursos para hacerlo valer. En esto precisamente consiste su calidad de justo.

$Y$ esto es precisamente lo que en la mentalidad de los israelitas que escuchan a Jesús evoca la expresión hebrea malkuth Yahwéh, reinado de Yahvéh. El pueblo de Dios experimentó la acción justiciera de Dios al ser liberado de la esclavilud de Egipto. Pero cuando dentro del mismo pueblo de Israel aparecen los abusos opresores, la escandalosa división entre pobres y ricos, tambiến entonces Yahvéh sale en defensa del débil —el huérfano, la viuda, el emigrante, el asalariado, el pobre,...- para hacer respetar su derecho. Hasta tal punto se muestra Dios parcializado hacia el lado de los pobres - y no sólo en los libros proféticos-que no faltan en el Antiguo Testamento textos que nos describen a Yahvéh no tanto como juez que da sentencia, sino como parte litigante que asume en el tribunal la defensa del pobre y oprimido y acusa al rico opresor. Basta una rápida lectura del Salmo 72, salmo de entronización real, para captar lo que entiende por un rey justo:

El hara justicia a los humildes del pueblo.

Salvará a los hijos de los pobres y aplastará al opresor.

...liberará al pobre suplicante, al desdichado al que nadie ampara;

se apiadará del débil y del pobre; el alma de los pobres salvará.

Por ello, cuando Jesús anuncia que viene el reino de Dios, lo que está anunciando es el ejercicio de la soberanía misericordiosa de Dios, que en un mundo injusto toma la forma de implantación de la justicia, reconocimiento efectivo de los derechos de los empobrecidos. Esto va a suponer un cambio radical de si- 
tuación para los pobres, condenados hasta ahora a condiciones inhumanas de vida, a morir y ver morir a los suyos antes de tiempo, por causa, en definitiva, de la prepotencia y explotación de los poderosos. Y esto, desde luego, no puede menos de sonar como buena noticia, como una gran noticia, en los oídos de los pobres. Aqui radica el sentido del "dichosos ustedes los pobres, porque para ustedes es el rèino de Dios." Significa el anuncio del fin de su opresión injusta, fuente de tanto sufrimiento y muerte. Las cosas van a cambiar, y van a cambiar para bien.

De este modo el hecho de que cambie realmente la situación de los pobres, de que se sequen las lágrimas del que llora, de que los pobres salten de gozo ante la buena noticia que trae Jesús, se convierte en la presentación programática de su misión y en el criterio fundamental para reconocerlo como mesías:

Yo para esto he sido enviado" (Lc 4,43).

El Espíritu Santo está sobre mí, porque me ha ungido para que dé la buena noticia a los pobres ( $\operatorname{lc} 4,18)$.

Vayan y díganle lo que han visto y oído (Mt 11,4).

Si lo que se proclama no es buena noticia para los pobres, no es el evangelio de Jesús. Por eso, la primera resonancia que el anuncio de reino produce cn los pobres es de alegría y dicha. Vendrá también después la llamada a ser congruentes con los valores del reino que viene, dejándose llenar y transformar por el amor misericordioso de Dios, pero lo primero es sentir el consuelo de esa presencia que pone fin a las causas de su aflicción. La primera palabra que la mujer adúltera oprimida escucha de Jesús es "nadie te ha condenado, vete." Pero ser beneficiado por la misericordia de Dios es llamada a hacerse misericordioso; la siguiente palabra es: "en adelante no peques más" (Jn 8,11).

\subsection{El dilema de los ricos}

Pero este cambio de situación de los pobres debe realizarse en un contexto en el que la relación entre pobreza y riqueza es causal y dialéctica. Los pobres son, antes que nada, empobrecidos por causa del acaparamiento y explotación de los ricos; y los ricos son enriquecidos a costa del empobrecimiento y miseria de las grandes masas. Liberar a los pobres dándoles acceso a las condiciones de vida que corresponden a su dignidad humana y de hijos de Dios, supone sacrificar los privilegios de los ricos opresores. Por eso, ante la noticia de que el reino de Dios viene, el rico se siente interpelado y llamado a acoger la benevolencia justiciera de Dios dejándose re-crear y transformar por ella en hermano y persona solidaria. "Conviértanse y crean la buena noticia" (Mc 1,15). Sólo la conversión, metanoia, cambio de mentalidad, ojos nuevos para ver la realidad con el amor solidario con que. Dios la mira, puede hacer que la cercanía del reino suene en los oídos del rico como buena noticia. Conversión al Dios que viene en gratuidad y benevolencia a rehacer las cosas, al Dios del reino. Pero convertirse a este Dios es convertirse al pobre y a su causa: "lo que hagan a uno de estos a mí me lo hacen." Y esta conversión es dura, es un cambio terriblemente radical que exige el des- 
centramiento de uno mismo, salir de la óptica de los propios intereses y privilegios individuales, de clase o de nación, para ponerse de parte de los intereses del pobre. "Daré, Señor, la mitad de mis bienes a los pobres; y si en algo defraudé a alguien le devolveré el cuádruplo" (Lc 19,8). En ese momento el reino de Dios se hace buena noticia para Zaqueo y la salvación entra en su casa.

Pero ¿qué sucede cuando el privilegiado que monopoliza el tener, el saber y el poder, utiliza su fuerza para retener ávidamente sus privilegios y se niega a convertirse a este Dios solidario con el pobre? Jesús plantea con crudeza la disyuntiva ineludible: "no puedan servir a Dios y a las riquezas." Ante la palabra, llena de amor, de Jesús que le pide "anda, vende lo que tienes y dalo a los pobres," el joven rico "se entristeció y se marchó apenado, porque tenía muchos bienes" (Mc 10,21-22). La palabra de Jesús se hace para ell mala noticia que produce tristeza.

Pero todavía peor, la cercanía del reino que viene a cambiar el estado de cosas en favor de los pobres, se presenta como amenaza a los intereses del rico. Interfiere con la ley del más fuerte, con la ley del egoismo. Y el rico que se aferra a sus privilegios no lo puede permitir: o habrá que quitar al evangelio esas peligrosas aristas y reducirlo a un discurso espiritualista que para nada afecta a la realidad o habrá que silenciarlo de modo delinitivo. La vida de Jesús está marcada por el conflicto con los poderes socio-religosos y políticos de su tiempo. Es consecuencia de su terca insistencia en no anunciar un Dios sin reino, sino un Dios comprometido con la vida de los pobres. La interpelación religiosa se hace al mismo tiempo interpelación social, y por ello subversión, que busca reestructurar la sociedad al modo como Dios la quiere. Los poderes del mundo entablan una guerra a muerte contra esta forma de concebir a Dios, contra esta buena noticia de los pobres. Jesús terminará siendo crucificado.

¿Cómo es posible que la bondad de Dios actuando humanamente en Jesús provoque ese rechazo y agresividad hasta la muerte y muerte de cruz? La parábola del buen pastor resulta iluminadora a este respecto. Buen pastor es el que se preocupa por la vida de las ovejas y, precisamente porque se preocupa, se ocupa de protegerlas eficazmente en su debilidad. Pero la calidad de bueno del buen pastor se manifiesta y verifica en que "da la vida por sus ovejas." Como que ocuparse por la vida de las ovejas y dar por ellas la vida son inseparables, son los rasgos esenciales del buen pastor. Pero ıpor qué? Porque existen lobos que se nutren de la muerte de las ovejas. Cuando el pastor bueno se interpone para defender a las víctimas, la fuerza destructiva del lobo sevuelve contra él. No porque le importe directamente el pastor, sino simplemente porque no lo deja caer sobre su presa. $\mathrm{Si}$, como el mercenario, el buen pastor pudiera ser comprado o atemorizado no habría por qué acabar con él. Pero buen pastor es el que, como deć́a Monseñor Romero y lo hizo realidad con su propia sangre, "no quiere seguridad mientras no le den seguridad a su rebafio." 


\subsection{Palabra y hechos: la contextura de la evangelización}

Despues de habernos detenido, aunque sea brevemente, en lo que es el contenido fundamental de la evangelización y en cómo ese contenido afecla a su portador y a sus destinatarios, digamos ahora una palabra sobre el modo concreto de realizar la tarea de la evangelización.

Hemos recalcado insistentemente que lo primero es la misericordia, el amor que se deja afectar por la situación del otro. Tras el gesto de ver y dejarse conmover por lo que ve, el impulso solidario de Jesús busca poner remedio a la acuciante situación del otro, comunicar vida a quienes no se permite vivir. Pero ¿como realizar este empefio?

Los sumarios con que los sinópticos sintetizan la actividad evangelizadora de Jesús contienen esta descripción fundamental: "recorría..., proclamando la buena noticia del reino, curando toda enfermedad y dolencia." La proclamación verbal de la buena noticia ha sido la forma usual, y hasta hace poco prácticamente exclusiva, de entender la evangelización. Sin duda que la trasmisión del mensaje evangélico por la predicación, la catequesis, la celebración litúrgica, etc., es elemento esencial de la tarea evangelizadora. Es la palabra la que ilumina el sentido de lo que acontece, es la palabra la que lleva al oído la buena noticia e invita a acogerla por la conversión, es la palabra la que explicila y celebra la presencia de Dios oculta en el curso de la historia, es la palabra la que desenmascara y denuncia a las fuerzas del antirreino que se resisten a su fuerza transformadora. Pero para ser evangelizadora, buena noticia, la palabra debe ser eficaz; palabra que realiza ya de alguna manera lo que anuncia, palabra existencial que se encarna, como el Verbo increado, en la historia y la trasforma desde dentro. En Jesús la palabra va acompaniada de gestos concretos que la realizan transformando la realidad y comunicando efectivamente vida: "los cojos andan, los ciegos ven, los muertos resucitan." Son estos hechos los que dan credibilidad a la palabra, como anticipaciones que comunican ya vida, aunque no sean la plenitud de la vida; que liberan de la opresión, aunque no sean la liberación final y plena de todas las servidumbres; que son presencia actuante del reino, aunque no sean la irrupción escatologica y definitiva del reino.

Pero palabra y hechos son las dimensiones existenciales a través de las cuales toma cuerpo histórico lo que es la realidad primaria de toda evangelización: el amor compasivo y misericordioso. Es este amor el que se hace unas veces palabra y otras obra o ambas al mismo tiempo, atendiendo a la situación concreta de los destinatarios. De nuevo resulta iluminadora la insistencia con que los evangelistas asocian al gesto de ver toda la actividad de Jesús, incluso la predicación o la interpelación personal: "viendo a la muchedumbre... les enseflaba diciendo...," "mirándole lo amó y le dijo..." Evangelizar no es repetir o hacer memorizar formulas esterotipadas, por logradas que parezcan. Evangelizar es pronunciar la palabra que se necesita, la palabra que resulta buena noticia en la situación existencial donde se encuentra el destinatario. Evangelizar es transformar la realidad de modo 
que el otro pueda vivir la vida que le corresponde como persona humana e hijo de Dios.

Si la insistencia va a recaer más sobre la palabra o sobre los hechos dependerá de la realidad misma donde se trata de hacer efectiva la presencia de la bondad de Dios. Ante la figura inconsciente que el samaritano encuentra en el camino, no parece que en un primer momento sea útil la palabra, sino la actuación para salvar esa vida y curar sus heridas. Pero llegara un momento en que las palabras podrán ser escuchadas y ayudar a iluminar el sentido hondo de unos hechos en los cuales se ha hecho presente, aunque esa presencia haya sido hasta entonces ignorada, el amor misericordioso de Dios actuando salvadoramente a través de! que ha sabido hacerse hermano.

Ambos, palabra y hechos, son la expresión concreta e historica de lo que Jesús es: transparencia en came humana de la misericordia de Dios; amor preocupado que viene a liberar y comunicar vida. De Jesús se dice que "recorrfa" los lugares; su amor no se queda quieto, sino que es amor impaciente del que fluye una manera de ser y de actuar que ya en sí misma es buena noticia. El que Jesús sea así, que hable como habla, que acoja como acoge a los pobres y pecadores, que se enfrente como se enfrenta con los poderes del mundo, que se fatigue y afane recorriendo los caminos de Palestina, que perdone como perdona a la pecadora, a los que lo crucifican, que muera como muere y resucite como resucita, en una palabra, que Jesús sea como es, es una buena noticia, porque en su humanidad, en lo que es, aparece el ser mismo, la bondad misma y ternura de Dios: "quien me ve a mí, ve al Padre" (Jn 14,9). El Dios que se ve en Jesús, no es el Dios arbitrario que impone temor y castiga al que viola el orden establecido, sino el Dios cercano y acogedor que quiere ante todo que todos los hombres vivan, pero sobre todo aquellos a quienes las estructuras pecadoras del mundo no dejan vivir: los pobres y pequeños de la tierra. Por eso, todo el acontecimiento Jesús es buena noticia.

\section{Ante el mundo contemporáneo}

Creo que lo que hasta aqui llevamos dicho esclarece bastante el camino que como evangelizadores debemos recorrer. Vamos, con Lodo, a tratar de explicitar algunos aspectos que pueden ser más relevantes en nuestro contexto actual.

\subsection{Las características del mundo de hoy}

Sin pretender, ni mucho menos, ser exhaustivos, varnos a recorrer sumariamente algunos de los rasgos característicos de este mundo contemporáneo nuestro en el cual debemos desarrollar nuestra vocación evangelizadora.

En primer lugar, está el fenómeno de la planetarización de la historia El enorme adelanto de las comunicaciones ha acortado de tal manera las dístancias que, por primera vez, podemos hablar con propiedad de una humanidad, una historia, de problemas sociales, económicos y políticos comunes a toda la humanidad. 
Se toma una decisión en el Kremlin o en la Casa Blanca y se producen miles de muertos e ingentes sufrimientos en Afganistán, Centroamérica, Angola o el Medio Oriente. Estomuda el presidente Reagan en Washington y se estremecen los grandes centros bursátiles de Europa, Asia o las Américas. Se aferra el Fondo Monetario Internacional a una política económica y son lanzados al desempleo y al hambre cientos de mineros y trabajadores en Bolivia, Brasil o Argentina. La proliferación de organizaciones internacionales, encabezadas por la Organización de las Naciones Unidas, expresan claramente la extensión e importancia de este fenơmeno.

Junto con esto, el acelerado avance de las ciencias y las tocnologías que llevan al espectacular dominio que de la naturaleza está adquiriendo la humanidad. La tecnificación que esto permite está trayendo indudables mejoras a la calidad de la vida de muchos hombres y mujeres y levanta renovadas esperanzas en los otros. Pero, por otra parte, es una tecnología monopolizada y celosamente custodiada -al menos en sus niveles más avanzados- por las sociedades más poderosas. Esto lleva a un aunento de la distancia que separa a fuertes y débiles y a la aparición de nuevos instrumentos y formas de opresión y explotación.

Es este un mundo superdesarrollado y con una impresionante oferta de bienes de consumo y de servicio, pero en el cual hay más pobres que nunca. En su reciente encíclica social, Juan Pablo II afinma: "dejando a un lado el análisis de cifras y estadísticas es suficiente mirar la realidad de una multitud ingente de hombres y mujeres, nifios, adultos y ancianos, en una palabra, de personas humanas concretas e irrepetibles, que sufren el peso intolerable de la miseria. Son muchos millones los que carecen de esperanza debido al hecho de que, en muchos lugares de la tierra, su situación se ha agravado sensiblemente" (n. 13). Este desarrollo insolidario no ha sido capaz de, teniendo las posibilidades técnicas para ello, erradicar la miseria que condena a muertes tempranas a tantos y tantos millones de seres humanos.

Este mundo está marcado por la insolidaridad y la desconfianza de unos para con otros. Un mundo dividido en bloques o grupos con intereses en conflicto: este-oeste, norte-sur, capital-trabajo, ricos y pobres, judíos y árabes, razas opresoras y razas oprimidas ... Mundos distintos dentro de este único mundo. Hoy hablamos de primer mundo, segundo mundo, tercer mundo y recientemente de cuarto mundo. Mundos con situaciones y condiciones muy contrapuestas. Un estudio hecho en 1983 y auspiciado por la Rockefeller Foundation y otras respetables instituciones calculaba que en el mundo se han dado desde la última guerra mundial unos 125 conflictos armados de gran envergadura, 95 de ellós en el tercer mundo, con el resultado de millones y millones de muertos. ${ }^{4}$ Sólo en Centroamérica llevanos más de 200.000 personas asesinadas desde 1978, muchas de ellas horriblemente mutiladas con derroche de crueldad. La producción de armamentos en 1985 alcanzo los 663.000 millones de dólares, casi 2.000 millones de dólares por día, es decir, tres veces el presupuesto anual de un pals de 5 millones de ha- 
bitantes como es El Salvador, mientras en el mundo cada día mueren 50.000 niños de pura desnutrición.

Es cierto que decenas de naciones, sujetas hasta entonces al arbitrio de los imperios, han accedido a independencia política en los últimos aftos, pero no es menos cierto que en vez de transformarse en naciones autónomas, preocupadas de su propia marcha hacia la justa participación en los bienes y servicios destinados a todos, se convierten en piezas de un mecanismo y engranaje gigantesco. Ha surgido una nueva forma de imperialismo.

Plaga típica y reveladora de los desequilibrios y conflictos del mundo contemporáneo, son los millones de refugiados "cuya tragedia se refleja en el rostro descompuesto de hombres, mujeres y niffos que, en un mundo dividido e inhóspito, no consiguen encontrar ya un hogar" (SRS 24). A esto se aftaden los inmigrantes ilegales que arriesgan los mayores peligros y humillaciones, acuciados por la necesidad, quienes son rechazados por una sociedad temerosa de ver reducidos sus niveles de vida al tener que compartir con más sus bienes y recursos.

Y podramos seguir enumerando caracter(sticas: terrurismo, deuda externa, analfabetismo, discriminación, desempleo, droga. T'odas ellas contribuyen a reforzar la imagen de un mundo que, en su globalidad, es inhóspito e inhumano, un mundo desolador, que nada tiene que ver con el proyecto de un Dios Padre que nos quiere a todos hernanos. Un mundo en el cual, si a niveles personales puede a veces darse, y se da, la sensibilidad humana y la solidaridad, a niveles estructurales tanto nacionales como internacionales, sigue reinando la ley de la selva. "Nuestros intereses vitales," "la seguridad de la nación," etc., son palabras altisonantes detrás de las que se esconden ídolos de muerte. Mucho más que el ateísmo que niega su existencia, el enemigo real del Dios de Jesús sigue siendo, en nuestro mundo, esta idolatria que sacrifica millones de víctimas humanas ante el altar del poder $\mathbf{y}$ del dinero.

$Y$ junto a todo esto va rugiendo entre los pobres una nueva conciencia de su dignidad y sus derechos. Derecho, en primer lugar, a la vida, ese minimo que es lo máximo, en expresión de Monsefor Romero. Y con ella, el derecho a perticipar en su propia historia y destino. Dios no quiere que las cosas sigan como están. "Desde el seno de los diversos paises del continente estí subiendo hasta el cielo un clamor cada vez más turnuluoso e impresionante. Es el grito de un pueblo que sufre y que demanda justicia, libertad, respeto a los derechos fundamentales del hombre y de los pueblos" (Puebla 87).

\section{Los desafios a la evangelización}

Y ahora nos planteamos la pregunta clave: ¿cóno evangelizar a un mundo así? ¿Cómo responder al "sordo clamor de millones de hombres que piden a sus pastores una liberación que no les llega de ninguna parte?" (cfr. Puebla 88) ı.Cómo hacernos para ellos buena noticia? En primer lugar, por lo que somos. Es 
la totalidad de nuestra existencia la que tiene que ser evangelizadora Es nuestra manera de ser Iglesia, es el estilo de nuestra vida como instituto religioso, como cristianos, nuestra manera de sibuamos ante la realidad de los otros, lo que tiene que ser buena noticia ante todo, hoy como en los tiempos de Jesús, para los condenados de la tierra, para los pobres y oprimidos de este mundo. Lo que somos, nuestro carisma y nuestra manera de vivirlo, tienen que resonar hoy en este mundo zomo un grito que proclama la misericordia de Dios y hace saltar de dicha a los que por nosotros reencuentran y alimentan su esperanza.

Ta Iglesia debe mirar a Cristo cuando se pregunta por su acción evangelizadora" (Puebla 1141), nos dicen los obispos latinoamericanos. Recordemos rápidamente, aplicándolo a nosotros mismos, lo que sobre "el primero y más grande evangelizador" hemos reflexionado.

Lo primero para nosotros hoy es dejamos evangelizar, acoger la buena noticia de la bondad misericordiosa de Dios y dejarnos configurar por ella hasta hacer de nuestras propias entraflas de misericordia su manifestación y cauce. Esto significa, como recordábamos hace un momento, conversión a los pobres y oprimidos, conversión al hermano en cuyo rosiro dolorido reconocemos "el rostro sufriente de Cristo, el Seftor, que nos cuestiona e interpela" (Puebla 31). Conversión que debe ser de toda la Iglesia, y de nosotros con ella, pues -y sigo citando a los obispos en Puebla- "no nos hemos comprometido suficientemente con los pobres" ( $C f r, \mathrm{nn} .1134$ y 1140). Conversión y reconversión continua donde el amor misericordioso vaya creciendo en nosotros y llevándonos a un siempre mayor compromiso e identificación con los pobres y su causa.

En un segundo momento, no tanto cronológico sino dialéctico, la misericordia toma ojos para ver con nueva hondura la realidad del pobre. En este nuestro mundo complejo, planetarizado, tecnificado, en el cual somos conscientes de que la pobreza y el dolor escandalosos de tantos no son debidos a causas puramente naturales, sino que son producto de sibuaciones y estructuras económicas, sociales y políticas, es necesario mirar con ojos misericordiosos ante todo, pero con la ayuda de cuanto instrumento puedan proporcionar las ciencias humanas y sociales para interpretar los datos que vienen de la realidad, de modo que esa mirada no sea ingenua sino critica. Ejemplo de esta nueva conciencia es el varias veces mencionado documento de Puebla $L a$ evangelización en el presente y en el futuro de America Latina. Su primera parte se titula: "Visión pastoral de la realidad latincamericana" Ninguna "cientificidad" puede sustibuir lo "pastoral" de esta visión; sigue siendo la misericordia el motor fundamental de la evangelización; pero ninguna misericordia acrítica y desiluminada podrá sustituir, en la complejidad de nuestro mundo, a una misericordia que en su búsqueda de respuestas eficaces a las necesidades reales no duda en mirar también a través del lente de las ciencias humanas y sociales para captar mejor el drama del mundo de hoy y poder discernir la palabra o la acción adecuadas.

Pero esta mirada pastoral no debe hacerse desde una atalaya distanciada y 
protegida, sino en la cercanía comprometida de la encarnación. Hay que acercarse a la realidad de aquellos para quienes debemos hacemos buena noticia. $Y$ acercarse es entrar en su realidad dolorida, dejamos conmover por la brutalidad de sus heridas. Es entrar en esa cultura de la pobreza, es sufrir la impotencia y marginación de los indígenas, la desesperación de los drogadictos, la amargura de las madres que lloran a los hijos que les han sido arrebakados. Hoy nos hemos hecho conscientes de esta caracteristica de la verdadera evangelización y hablamos mucho de encarnación, inculturación, inserción, quizás a veces sin captar todo lo que esto exige de anonadamiento, de vaciamiento de uno mismo. Se trata de dejarse hablar, dejarse ensefar por la realidad y la experiencia del otro, sin prisas, pacientemente. En nuestro continente la primera evangelización se hizo a la sombra de la espada, se derribaron por la fuerza divinidades y culturas, se impuso la fe junto con expresiones religiosas y símbolos extraflos. Hoy la jerarquía nos habla de una nueva evangelización, hecha desde dentro, desde el corazón mismo de las culturas marginadas, en absoluto respeto a la identidad y libertad de los pueblos.

De esta visión y acercamiento brotará la compasión. La pasión del otro que se hace también mi pasión, su dolor que me duele en mi propia came. Y de ahí la urgencia a hacer algo que alivie el dolor, que elimine las causas que lo producen. Será una palabra que consuela, que anuncia o que denuncia; o será una acción concreta que ayuda a romper cadenas o a abrir horizontes de esperanza.

Hay diversas maneras de acercarse cristianamente a la realidad de los pobres. No hay que pensar que el acercamiento que permite captar la situación del otro y actuar sobre ella tiene que ser necesariamente para todos acercamiento geográfico. En este mundo planetarizado y con modernos medios de comunicación, la información vuela. La solidaridad entre las comunidades permite estar muy bien enterado y muy cercano a las necesidades de los pobres y actuar sobre ellas potenciando la acción evangelizadora de quienes sí están físicamente insertos en ellas. La imagen del cuerpo que actúa por medio de órganos diversos ilustra hoy mejor que nunca las posibilidades de acción misionera de la Iglesia. Es la solidaridad orgánica que potencia la capacidad de servicio del todo. Puedo dar testimonio de primera mano de cómo son buena noticia en El Salvador esos cristianos -y sacerdotes y religiosas entre ellos- que desafian las leyes que injustamente prohiben la acogida a los pobres desplazados extranjeros; me refiero al movimiento Sancruary. O cómo hacen más creible nuestra proclamación del evangelio esos hombres y mujeres que en las escalinatas del Capitolio luchan por la causa de la paz en Centroamérica o de los acosados inmigrantes mexicanos. Nadie puede estar en todas partes ni agolar todas las posibilidades de acción evangelizadora. Ni el mismo Jesús quien, precisamente por hacerse carne humana, se anonadó y limitó a un puntito en las coordenadas espacio-temporales de la historia. Somos nosotros los que le debemos dar cuerpo histórico concreto en nuestro espacio y nuestro tiempo. Pero la Iglesia como un todo sí es enviada "a todas las gentes," "hasta los confines del mundo," para ser sacramento de salvación y anunciar y realizar la buena noticia del reino. 
Permítanme seguir ilustrando esta exposición desde la concreción de mi propia Iglesia salvadoreña Para contribuir a la evangelización de El Salvador es necesaria la presencia encarnada de cristianos, sacerdotes, religiosas y religiosos, misioneros que entren en la realidad, historia y cultura de ese pueblo, y asuman in situ la lucha crucial por la vida y la liberación; que estén dispuestos a llevar su testimonio hasta el martirio. Ita, Dorothy, Maura, Jean, junto con Monseñor Romero y tantos otros mártires siguen hoy siendo buena noticia para los pobres de El Salvador. "Mientras haya gente que, como ellos, lo dejan todo para venir a convivir, sufrir y luchar con nosotros y a morir como nosotros y por nosotros tendremos esperanza, porque sabemos que el Dios de la vida no nos ha abandonado," decía una anciana salvadoreffa cuando hace poco tiempo celebraban en un campo de refugiados la memoria de las mártires norteamericanas.

Solidaridad es dar y recibir. El evangelizador es evangelizado. La fe y espe-. ranza, el acogimiento agradecido, la alegría con que esos pueblos celebran la vida y la fortaleza con que asumen la muerte, el que sean como son, todo esto se hace de mil maneras buena noticia que da sentido, gozo y ternura al evangelizador. En ellos se hace presente Cristo, más crucificado que glorioso ciertamente, pero ahí está reconocible para el que tiene ojos para verlo. Decía Monseflor Romero: "con este pueblo no cuesta ser buen pastor." Es la experiencia de la fuerza que el Seftor da a través del pueblo que, como en tiempos de Jesús, se agolpa esperanzado alrededor de la buena noticia y encuentra en ella la fuerza para proseguir su lucha liberadora.

Y, finalmente, no debemos olvidar que buen pastor es quien da la vida. "Dichosos ustedes cuando los injurien, los persigan y calumnien por mi causa..., esto hicieron también con los profetas anteriores a usledes" (Mt 5,11). El mundo se sigue resistiendo a dejarse transformar por el reino. Las fuerzas del antirreino son terriblemente poderosas y hábiles. Saben ocultar el mal, deformar la verdad, dividir y, cuando les parece necesario, aplastar brutalmente. Monseffor Romero, los miles de mártires que jalonan la reciente historia de América Latina, son prueba fehaciente de ello. En este mundo hay que pagar un precio por asumir la causa del pobre, un precio que no consiste en el fondo, sino en correr su misma suerte y destino de desprecios, opresiones y represiones. Pero ¿qué es lo importante para la Iglesia, para nuestros institutos religiosos: ser bien mirados y apoyados por los poderosos del mundo o ser un grito de esperanza, una buena noticia para los despreciados de la tierra? También a la Iglesia y a nosotros, institucionalmente, se aplican la palabras de Jesús: "si uno quiere salvar su vida la perdera; en cambio el que pierda su vida por mi la encontrará" (Mt 16,25).

\section{Conclusión}

Al final de este recorrido tres cosas al menos parecen quedar claramente asentadas: sólo de la raíz de una misericordia que se traduce en solidaridad activa puede brotar una auténtica evangelización; cualquiera que sea la forma que la evangelización asuma, será siempre criterio insustituible de su cualidad de 
cristiana su capacidad de ser en verdad "buena noticia" para los crucificados de nuestra historia; hay un precio que pagar, "rescate por muchos" (Mc 10,45), por la fidelidad a la misión evangelizadora dentro de un mundo dividido y pecador.

Desde cualquiera que sea nuestro carisma específico dentro de la Iglesia debemos dejarnos cuestionar y afectar por los sufrimientos de nuestro mundo y buscar continuamente, bajo la gufa del Espíriu, cómo acercamos a él de modo que en verdad seamos buena noticia de Cristo. Modelo ejemplar de este talante evangelizador es María, tipo de la Iglesia evangelizadora. Es "la esclava del Seffor" quien se pone incondicionalmente al servicio liberador del Dios que se acerca en bondad y misericordia. Ella da a la Palabra su carne humana. Ella la entrega a la humanidad. En ella se integran, sin reduccionismos de ninguna clase, las dos dimensiones esenciales de la evangelización, la que une con el que envia: el Padre del que viene toda salvación; y la que une con aquellos a los que la misión nos remite: los pequefios de la tierra. Maria es "toda de Cristo y, con El, toda servidora de los hombres" (Puebla 294). El misterio de la visitación es un hermoso compendio de lo que la Iglesia debe ser. Con Cristo hecho came en sus entraftas se lanza a los riesgos del camino para acercarse a aquella cuya situación le ha sido revelada como signo. Por su ser y hacer que, desde la sencillez, irradia la bondad salvadora que porta en su seno, se hace buena noticia para Isabel, para el Bautista, para esos pobres a los que en el Magnificat anuncia la alegria de un Dios que hace maravillas en los pequeños como ella, mientras derriba de sus tronos a los poderosos.

Que el ejemplo de María nos ayude a discemir los signos de los tiempos y, fieles, tanto al Cristo que nos envía como a los pobres a los que somos enviados, encontrar el camino de la evangelización que el mundo modemo necesita.

\section{NOTAS}

1. Este artículo es la reelaboración de una ponencia presentada ante 1.400 religiosas de la Congregation de Notre-Dame en el "Congreso sobre la misión" tenido en Montreal del 29 de julio al 3 de agosto de 1988.

2. En adelante citaremos con frecuencia los dos más importantes documentos eclesiales sobre el tema: Pablo VI, Evangelii Nurtiandi, Rome, 1975, (EN); y III Conferencia General del Episcopado Latinoamericano, La evangelización en el presente y el futuro de América Latina, Puebla, 1979, (Puebla).

3. Juan Pablo II, Sollicitudo Rei Socialis, Roma, 1988, (SRS).

4. Cfr. N. Chomsld, La quinsa libersad, San Salvador, 1987, 26-27. 